\title{
Proyectos barrocos para la Seu d'Urgell
}

Juan Bassegoda Nonell

De un tiempo a esta parte parece como si se hubiera iniciado un movimiento en defensa de la arquitectura barroca y, especialmente de la que, en los siglos XVII y XVIII, se superpuso a los muros y bóvedas de las iglesias medievales.

César Martinell Brunet (1888-1973), el centenario de cuyo nacimiento se conmemoró en 1988, fue arquitecto y profesor de la Escuela de Artes y Oficios de Barcelona. Fue también un pionero de los estudios del barroco con su libro sobre los escultores Bonifàs ${ }^{1}$ y los tres volúmenes sobre arquitectura y escultura barrocas en Cataluña ${ }^{2}$.

Con anterioridad el desprecio por lo barroco fue evidente durante lustros. El movimiento neoclásico fue especialmente agresivo con el arte barroco y no menos agresiva fue la actitud de los restauradores románticos de monumentos, empeñados en devolver el aspecto medieval de las iglesias con total desprecio por los añadidos posteriores. La Carta de Venecia de 1964 fue el primer documento internacional que se mostró contrario a tal proceder ${ }^{3}$. 1917.

MARtinell, C., Llibre dels Bonifàs, Escultors setcentistes. Barcelona, Ed. Castells,

2 Martinell, C., Arquitectura i escultura barroques a Catalunya. Monumenta Cataloniae, Barcelona, 1963.

${ }^{3}$ Carta de Venecia. De Re Restauratoria, Vol. II. Barcelona, Ed. Universidad Politécnica de Barcelona, 1974, págs 13-15. 
Para muestra basta un botón, y este puede ser un fragmento de Juan Agustín Ceán Bermúdez en su descripción de la catedral de Sevilla ${ }^{4}$.

Dice asi este conocido anticuario: «Parece que no podian pasar más adelante los desaciertos y monstruosidades con que los pintores habian afeado la arquitectura del siglo XVII, pero otros artistas más ignorantes y más osados la tomaron por su cuenta a principios del siglo XVIII y la desfiguraron de tal modo que, inundaciones de gentes bárbaras y centenares de años no harian tanto estrago, ni causarian tanta diferencia como se nota en Madrid entre la fachada de las Descalzas Reales y el inmediato portal de la capilla del Monte de Piedad y, en Sevilla, entre la puerta de Triana y la del Colegio de San Telmo.

Desde que los pintores empezaron en el siglo XVII a separarse de las leyes de la arquitectura, comenzó este arte a correr a su ruina, y no paró hasta que lo sepultaron en el XVIII los albañiles y retableros y los tallistas levantando en su lugar otro nuevo arte, o conjunto de despropósitos, parte de una fantasía desordenada, de una independencia absoluta de los preceptos de la arquitectura y de una total libertad para poder girar a su arbitrio por donde les conducia su misma fantasia desarreglada".

Ceán, como queda manifiesto, se expresa sin pelos en la lengua y un poco más abajo califica al Sagrario de la Cartuja del Paular, la Sacristía de la de Granada y la de la catedral de Córdoba, como "los primeros abortos de esta nueva secta, culminando con el Transparente de Toledo, que es la maravilla de los desatinos arquitectónicos".

El caso es que hasta tiempos muy recientes este sentimiento ha continuado presidiendo buen número de restauraciones como el desmontaje de los restos del altar mayor de Santa María de la Mar en Barcelona (1967), la limpieza interior de la catedral de Valencia y otros muchos ejemplos de la segunda mitad del siglo xx, dentro y fuera de España. La única diferencia es que al desprecio por el barroco, han unido los restauradores recientes, el que sienten por el neoclásico. Así este estilo pagó con hierro el daño que con hierro diaiéctico había infligido al barroco. Basta para ello leer las opiniones de Antonio Ponz, Secretario que fue de la Real Academia de las Tres Nobles Artes de San Fernando de Madrid.

"Cean Bermudez, J. A., Descripción artistica de la catedral de Sevilla. Sevilla, Imp. y Lib. de D. A. Álvarez, 1863, págs. 96-97. 


\section{EL CASO DE LA CATEDRAL DE LA SEU d'URGELL}

En la ciudad de La Seu d'Urgell, capital de la comarca de L'Alt Urgell, provincia de Lérida, se levanta una fastuosa catedral románica que es la sede del obispo de esta diócesis, la más grande de Catalunya que se extiende además a Andorra de la que el obispo es Co-principe.

La catedral actual es del sigio XII, sucesora de otras dos anteriores, construida por un maestro italiano según el gusto lombardo.

Una vez terminada se le adosó, en el siglo XIII, un interesante claustro labrado en oscura piedra granitica.

Este claustro es de arcos de medio punto con columnas sencillas y techo de madera y pizarra. En los capiteles se representa toscamente la fiora corintia, animales fantásticos y los horrores del infierno.

El claustro perdió enteramente uno de sus lados, el que afronta el Capítulo, en 1603, siendo substituidos arcos, columnas y capiteles por una anodina logia de arcos de medio punto sobre pilares rectangulares, que labraron los maestros Francisco Bolet y Pedro Bòria. Algunos capiteles fueron a parar a una fuente pública de La Seu y luego al Museo de Maricel de Sitges.

También dentro del siglo XVII, en 1631, por encargo del Deán Francisco Morillo se rehizo el retablo mayor copiándolo del de la catedral de Barcelona, actualmente en la parroquia de San Jaime. El retablo de 1631 fue vendido y exportado a Estados Unidos.

Pero la gran reforma interior se hizo entre 1766 y 1768 por el arquitecto, o maestro yesero, Antonio Guinot, quien recubrió los paramentos, pilastras y bóvedas con más de 50 toneladas de yeso formando un orden compuesto que escondió la estructura románica.

Este recubrimiento barroco, o neoclásico según se mire, fue destruido entre 1918 y 1919 por el arquitecto José Puig y Cadafalch quien, en su libro de $1916^{5}$ tiene muy duras palabras para la obra de Guinot: "En l'any 1766 , de trista recordança, sentint-se influits de la pruija de renovació d'aquells migrats temps, decidiren (els canonges) fer enguixar i enlluir tots els paraments de l'interior, encarregant-se d'executar tan dissortat projecte mestre Anton Ginot, qui demostrà tenia major traça en

\footnotetext{
Puig y Cadafalch, J., Santa María de la Seu d'Urgell. Barcelona, 1918, págs. 87-91.
} 
destruir l'obra antiga, trencant columnes i capitells i esbocinant cornises, que no en compondre l'arrebossat que en mala hora li encarregaren".

Dentro del coro general de denuestos contra la decoración de yeso cabe también la excepción que se puede leer en el texto de Pascual Madoz en su Diccionario Geográfico ${ }^{6}$. "El estilo que dominaba en todo este edificio era el gótico (sic), pero desapareció con otro de orden compuesto, con que fue recubierto aquel y que, siendo de mayor gusto, hace del interior de la catedral un hermoso templo". Catorce años separan los elogios de Madoz de las invectivas de Ceán ${ }^{7}$.

Puig y Cadafalch hizo el proyecto de limpieza interior en 1915 al tiempo que publicaba, en colaboración con el archivero diocesano, su libro sobre la catedral. Apenas unas malas fotografías permiten conocer el aspecto de la catedral antes de 1918 pues no se tuvo cuidado de levantar unos planos de lo que se hizo desaparecer ${ }^{8}$.

Estas obras fueron realizadas pero hubo otras que no pasaron de proyecto y que bien merecen un comentario.

\section{INTENTO DE SUBSTITUCIÓN DEL CLAUSTRO}

En 1781 el cabildo encargó un proyecto que suponía el total derribo del claustro románico, incluida el ala o panda de 1603, y la subsititución por otro trazado dentro del más ortodoxo neoclasicismo. El proyecto inicial, de orden corintio, era de Antonio Cabot y la reforma del mismo, con pórtico dóricos y toscanos, de Jacinto Sala, alias Marsal, de Vic, en 1790.

Es evidente que el claustro románico debía contrastar mucho con el interior de la iglesia enyesada y decorada con un orden compuesto y tal hecho debió decidir al cabildo a modificar un claustro que, a sus ilustrados ojos, debía presentarse como bárbaro y primitivo.

${ }^{6}$ Madoz, Pascual, Diccionario Geográfico. Vol. XIV, Madrid, 1846, pág. 175.

'BASSEgOda NONELL, J., "La revolución francesa salvó el claustro de la Seu d'Urgell", La Vanguardia. Barcelona, domingo 13 de noviembre de 1988, pag. C-16.

${ }^{8}$ La restauración de la catedral por Puig de Cadafalch fue duramente criticada por LAZARo José, en El vandalismo en una catedral, Madrid, 1925. Habla de la venta del coro gótico, parte del cual compró el autor del artículo, y la substitución por otro neo-románico proyectado por Puig. 
En 1791 aún no se habian iniciado los trabajos y Cabot, desde Gerona escribió al Cabildo instando el comienzo de las obras.

\section{UNA GUERRA OPORTUNA}

La Revolución Francesa, iniciada en 1789, provocó una serie de desmanes que decidieron a las potencias europeas a declarar la guerra al nuevo régimen galo. El rey Carlos IV de España estaba decidido a salvar al monarca francés, el desgraciado Luis XVı que tan mala muerte hubo en el patíbulo.

En principio los ejércitos españoles batieron bien a las desorganizadas tropas revolucionarias pero pronto, después de la fracasada toma del puerto de Tolón, cambió la suerte y fueron los franceses los que pisaron suelo español. El 23 de agosto de 1793 los franceses invadieron Cerdanya y establecieron su campamento en Bellver.

El Obispo de La Seu d'Urgell, don José Boltas, ante la vecindad de los invasores, pasó a Guissona y el Cabildo catedralicio se refugió en Ponts. En 1794 los franceses ocuparon La Seu d'Urgell y saquearon la catedral, cosa de la que el obispo informó a Carlos IV.

En 1795 se cambiaron las tornas y las tropas del general español don José de Urrutia liberaron la ciudad lo que permitió el regreso a la misma del Cabildo. No asi del obispo que murió en Guissona el 8 de diciembre de 1795.

Con la guerra y las calamidades quedó definitivamente olvidado el proyecto para la refacción de los claustros.

\section{UN INTENTO DE RESTAURACIÓN ROMÁNTICA}

La catedral de La Seu d'Urgell fue estudiada por el arquitecto Pascual Sanz Barrera (1870-1918) a partir de 1903. Redactó una extensa memoria y preparó un proyecto de restauración muy completo que, por supuesto, comprendía la "descostración" de los revocos y enlucidos de yeso del interior. 
La memoria del proyecto, en forma de monografia, fue publicada en 1906 y reproducida en el Anuario de la Asociación de Arquitectos de Cataluña de 1907. Le valió el título Socio de Mérito y la medalla de plata del concurso convocado por la Sociedad Económica de Amigos del País en 1905 y la medalla de 2. ${ }^{a}$ clase de la Exposición Nacional de Bellas Artes de 1904 y el título de socio de honor del círculo de Bellas Artes de Madrid.

\section{LOS PLANOS DE ARCHIVO DIOCESANO DE LA SEU D'URGELL}

El interés y la inquietud de un avispado estudiante de arquitectura, Juan Morell Núñez, fervorosamente enamorado de la catedral de Urgell, por el barroco existente y el desaparecido, le llevaron al Archivo Diocesano para tratar de localizar cuantos planos existieran sobre la catedral.

Gracias a la amabilidad del archivero, don Benigno Marqués, pudo analizar un conjunto de rollos de papel guardados en dos cajones del archivo.

No contienen dibujos medievales, ni renacentistas, todos ellos son de los siglos XVIII, XIX y XX.

No existe el proyecto de Antonio Guinot para el recubriento interior con yeso en 1766 , pero hay elementos de estudio suficientes como para intentar un catálogo y una glosa de tales documentos.

Estos planos fueron examinados y en parte comentados por Sanz en 1906 y Puig y Cadafalch en su libro de 1916, pero nunca se ha intentado el estudio sistemático de los mismo.

El autor de esta comunicación se desplazó a La Seu d'Urgell el 20 de septiembre de 1988, excitada su curiosidad por la existencia de tales planos que, aun habiendo sido comentados por Puig, no han sido reproducidos hasta el momento. Pensó el autor de estas líneas que un Congreso Internacional de Historia de los Pirineos bien pudiera ser lugar donde encajara una comunicación sobre estos planos inéditos. Al poco tiempo envió a La Seu a un fotógrafo para disponer de las reproducciones de tales documentos.

La comunicación no pretende ser el catálogo definitivo de los planos del Archivo Diocesano. Se trata solamente de un primer inventario con 
algunos comentarios que podrán ser ampliados y redondeados en el sucesivo catálogo.

El inventario sucinto de los planos estudiados y las fotografias, de Francisco Ribera, de algunos de ellos, componen la comunicación que servirá para dar a general conocimiento la forma de dibujar y de proyectar de los arquitectos de la segunda mitad del siglo XVIII.

Es un estudio interesante ya que se hace sobre proyectos no realizados o sobre otros que, habiéndose realizado fueron luego victima del cambio de gusto.

El barroco fue un período vital y excitante que dió por fruto dinámicas y coloreadas formas que hicieron las delicias de las gentes diezyochescas y despertaron la ira y el odio de la generación siguiente.

A esta generación pertenece una serie de proyectos guardados en el Archivo de La Seu correspondientes a la construcción de la capilla del Santisimo y la Sacristía, a partir de 1832, según proyecto de Pablo Bertran. Solo se construyó el Sagrario que fue demolido sin piedad en la restauración de los años setenta. Tal circunstancia incrementa el valor de los planos, únicos testigos de ambas construcciones adosadas a las naves y cabeceras de la catedral.

De la demolición de la capilla del Sagrario solamente se salvaron las pinturas murales que pasaron al Museo de Arte de Cataluna en Barcelona. 


\section{BIBLIOGRAFIA}

MADOz, Pascual: Diccionario geográfico-éstadístico-histórico de España y sus posesiones de Ultramar. Tomo XIV, Madrid, Imprenta del Diccionario, 1849, pág. 175.

Piferrer Pablo y Pi y Margall, Francisco: “España. Sus monumentos y artes. Su naturaleza e Historia». Cataluña, Tomo II. Barcelona, Ed. D. Cortezo y Cía, 1884, págs. 340-342 (Nota de Antonio Aulestia Pijoan).

Sanz BarRera, Pascual: "Monografía y Restauración de la catedral de la Seo de Urgel', Anuario de la Asociación de Arquitectos de Cataluña, Barcelona, 1907, págs. 39-153 (Hay separatas de julio de 1906).

ROCAFORT, Ceferi: "Provincia de Lleyda", Geografia General de Catalunya, de F. Carreras Candi. Ed. Albert Martín, Barcelona, s.a. (1916) págs. $472-478$.

Puig y Cadafalch, Josep y Pujol Tubau, Pere: Santa Maria de la Seu d'Urgell. Barcelona, Ed. Heirich y Cía, 1918.

Puig y Cadafalch, Josep, de Falguera, Antoni, Goday, Josep: L'Arquitectura romànica a Catalunya. Vol. III, 1. Barcelona, Institut d'Estudis Catalans, 1918, pág. 348-358.

FolCh y TORRES, J.: El arco del antiguo coro de la Seo de Urgel, BarceIona, Editorial Catalana, 1919.

LÁzARO GaLdIANO, José: El vandalismo en una catedral, Madrid, La España Moderna, 1925.

Calzada Echevarría, Andrés: "Historia de la Arquitectura en España". Apéndice la Historia de la Arquitestura de Sir Banister Fletcher. Parte

1. ${ }^{\mathrm{a}}$, Volumen 2. ${ }^{\circ}$, Barcelona, Ed. Canosa, 1928, pág. 819.

SerRa y Boldú, Valeri: Seo de Urgel, Barcelona, Biblioteca de Turismo de la Sociedad de Atracción de Forasteros, XXIII, 1930.

LAMPÉREZ ROMEA, Vicente: Historia de la arquitectura cristiana española, Volumen II. Madrid-Barcelona, 1930, Espasa-Calpe, S.A., pág. 37-40. 
Pujol Tubau, Pere: “El retaule de la Seu d'Urgell», Miscel.lània Rubio i Lluch, Barcelona, Institut d'Estudis Catalans, 1936.

MonREAL y TEJADA, IUIS: Las cien mejoras obras de la arquitectura española, Barcelona, Ediciones Selectas, 1945, págs. 67-69.

Pujol Tubau, Pedro: "La catedral de Seo de Urgel», Ilerda, núm. 8, Lérida, 1947, págs. 43-48.

Corts Peyret, Juan: Historia de la Seo de Urgel, Barcelona. Ed. Vicente Ferrer, 1953.

Verrié, F. P.: “Arquitectura románica”, L'Art Catalá, Vol. I. Barcelona, Ed. Aymà, 1955, págs. 164-165.

JUNYENT Mn. Eduard: "Catalogne roman". Vol. II, Zodiaque. La nuir des temps, Sante-Marie-de-la-pierre-qui-vire, 1961, págs. 37-40.

MARTINELl i BRUNet, Cèsar, "Arquitectura i escultura barroques a Catalunya Monumenta Cataloniae", Vol. XII, Tercer volum. Barroc acadèmic (1731-1810), Barcelona, Editorial Alpha, 1963, págs. 60 i 104.

Serda Prat, Luis: Seo de Urgel. Guia de la ciudad, Andorra, Talleres: "Casal i Vall», 1964, págs.11-19.

ChueCA Goltia, Fernando: Historia de la Arquitectua española Edad antigua. Edad Media. Madrid, Ed. Dossat, 1965, pág. 162-163.

DE Dalmases, Nuria i PITARCH, Antoni José: «Els inicis de l'art romànic (siglo (X-XII)", Històrica de l'Art Catalá, Vol. I. Barcelona, Edicions 62, 1983.

SUREDA PONS, Joan: “Arquitectura románica», Historia de la arquitectua española. Vol. I. Barcelona, Ediciones Planeta, Barcelona. Exclusivas de Ediciones. Zaragoza, 1985, págs. 240-241. 


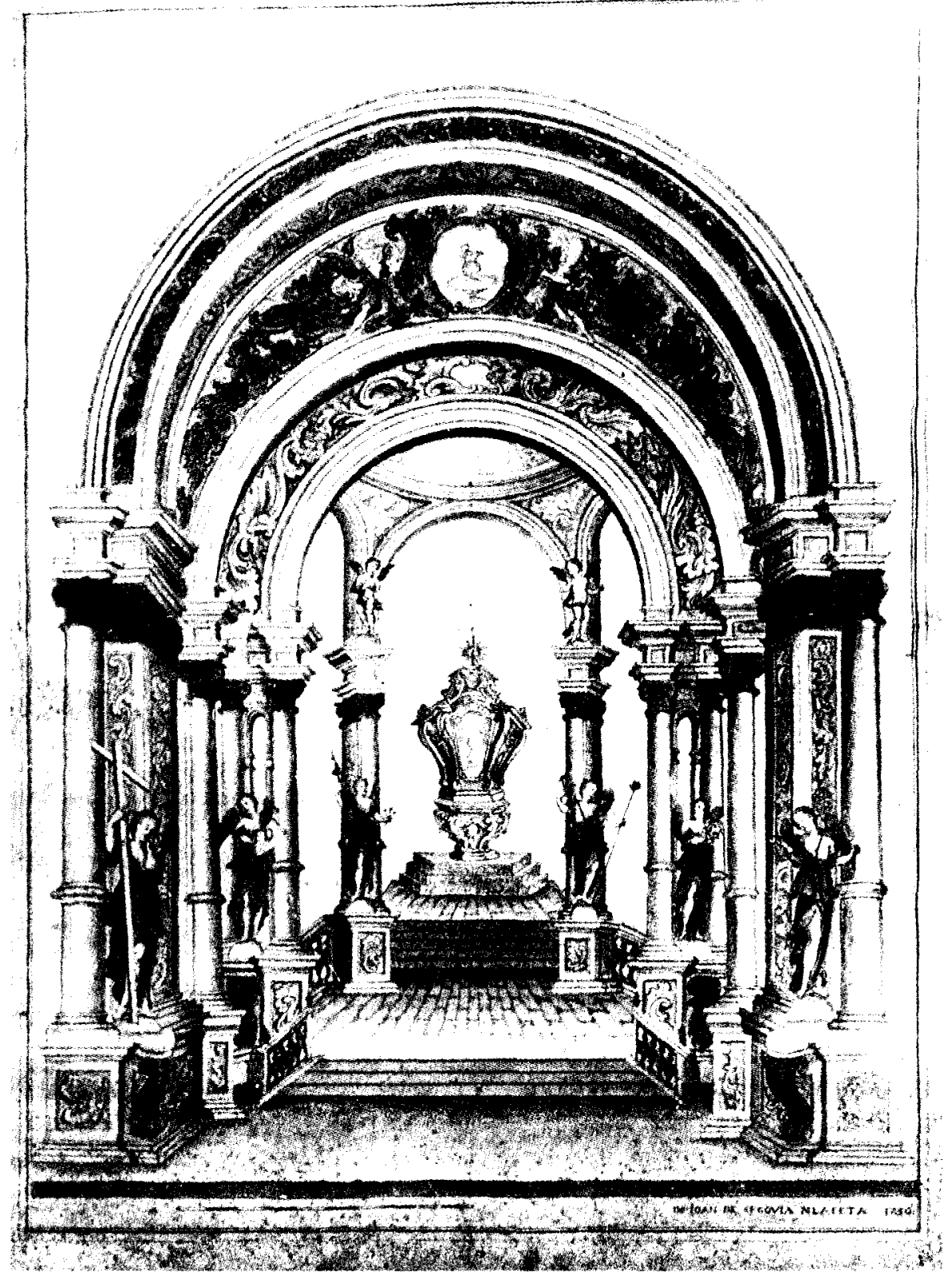

Fig. 1. Proyecto de monumento de Semana Santa. "Joan de Segovia meafeta" (1736) Acuarela. 


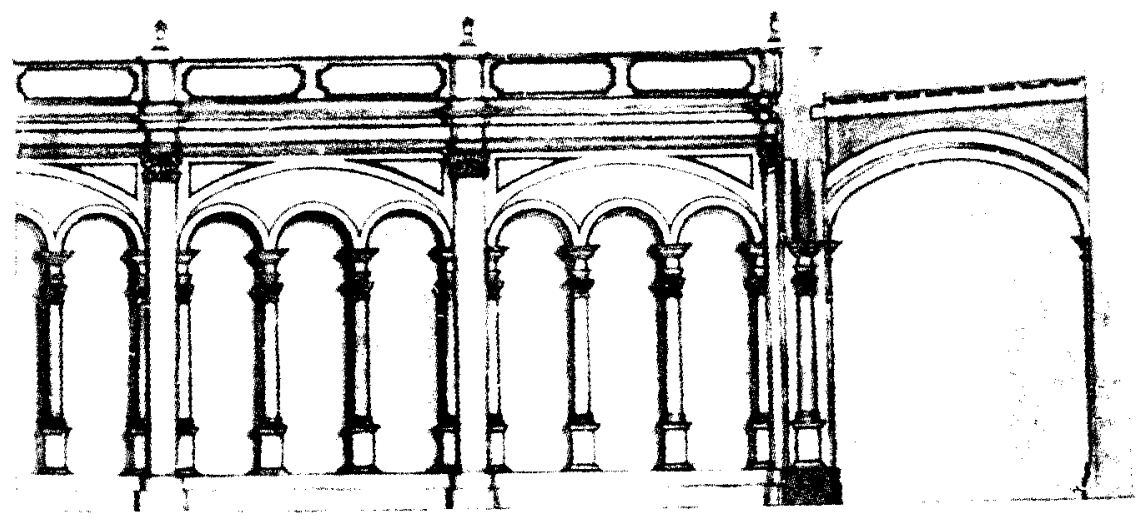

Fig. 2. Alzado del Claustro. Agustín Cabot (1781).

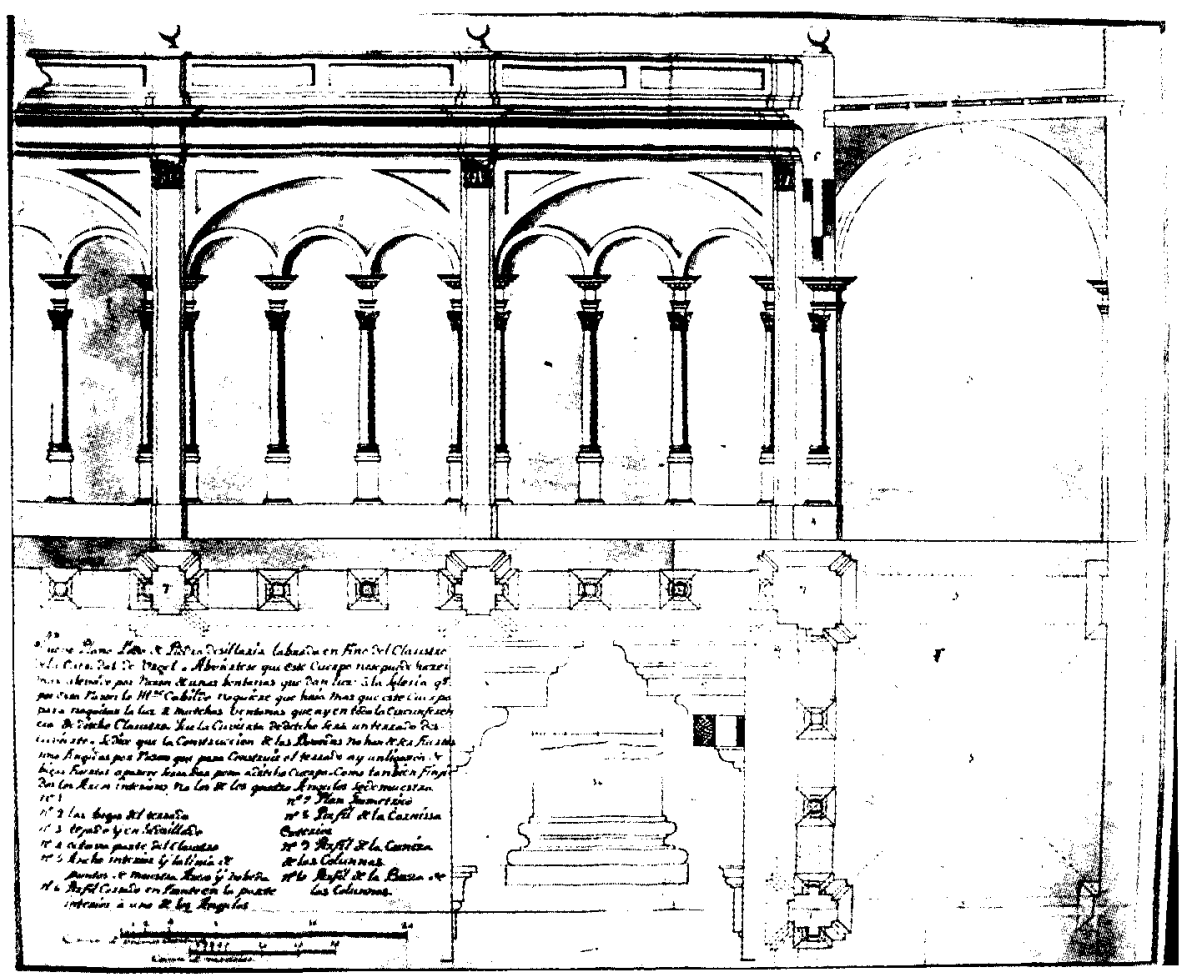

Fig. 3. “Nuevo plano de todo de piedra...". Proyecto de Agustín Cabot (1781). 


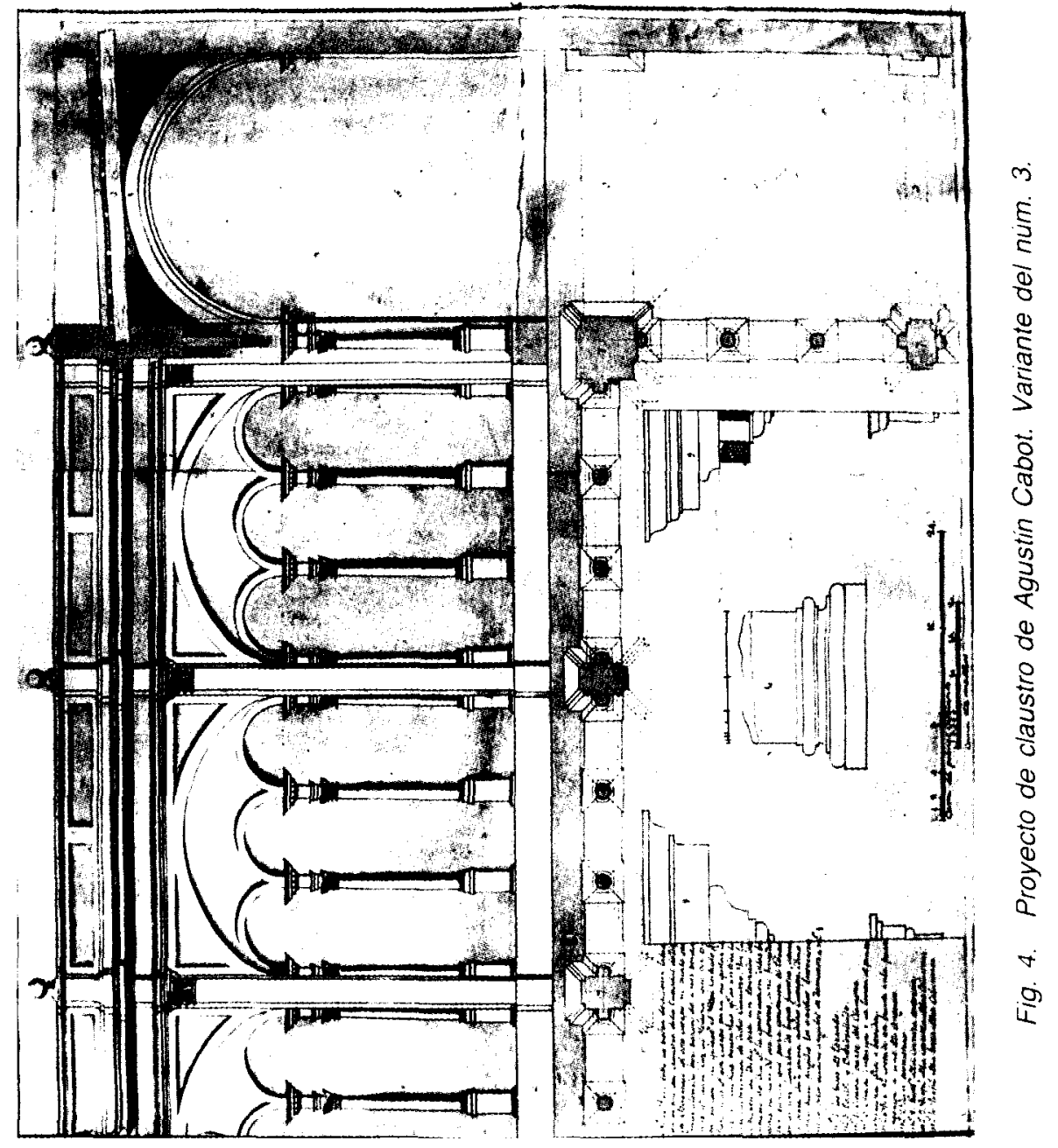




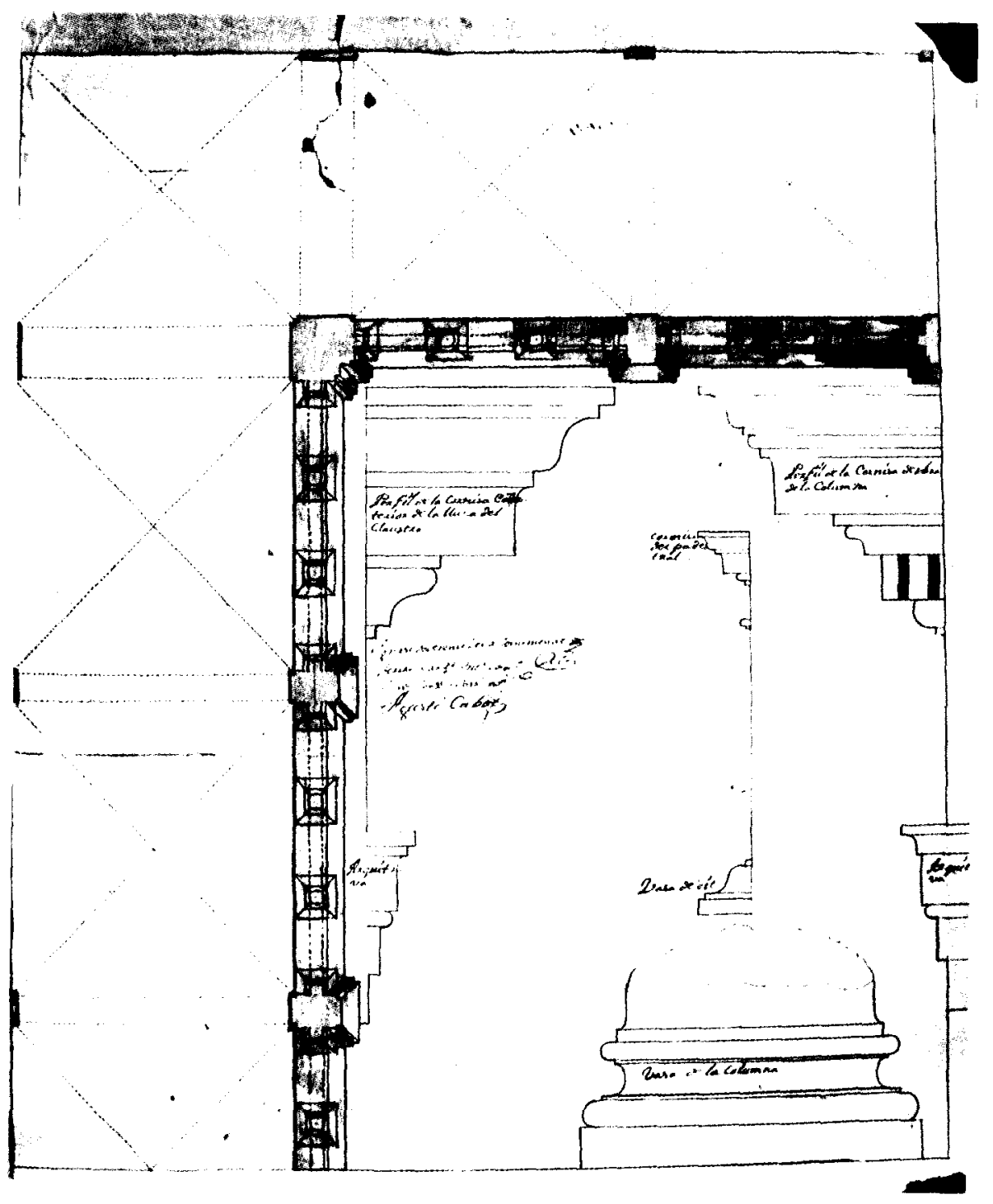

Fig. 5. Planta del claustro segun Agustin Cabot. Firmado por el arquitecto y tres canónigos. 


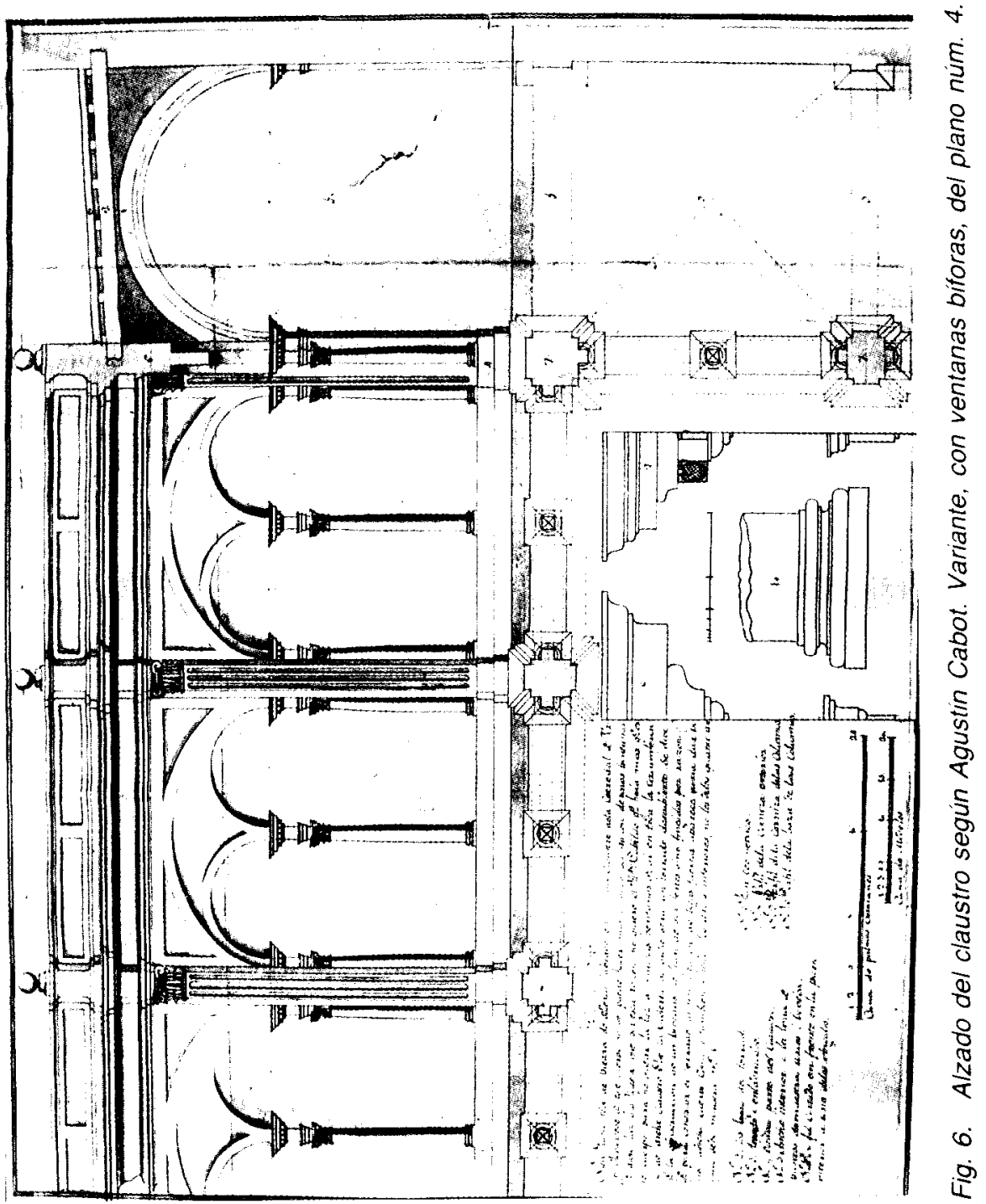




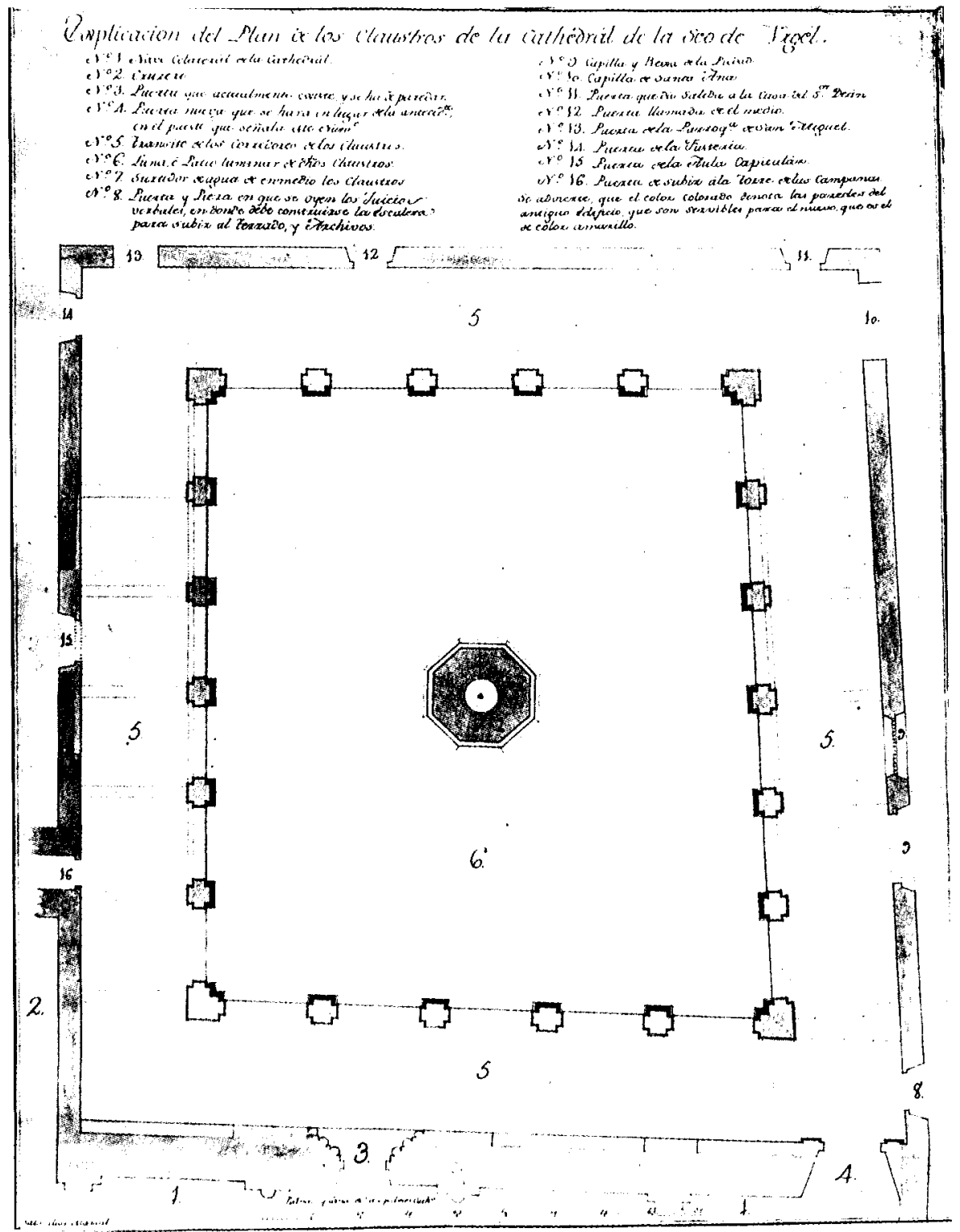

Fig. 7. Planta del claustro según Jacinto Sala (a) Marsal (1790). 


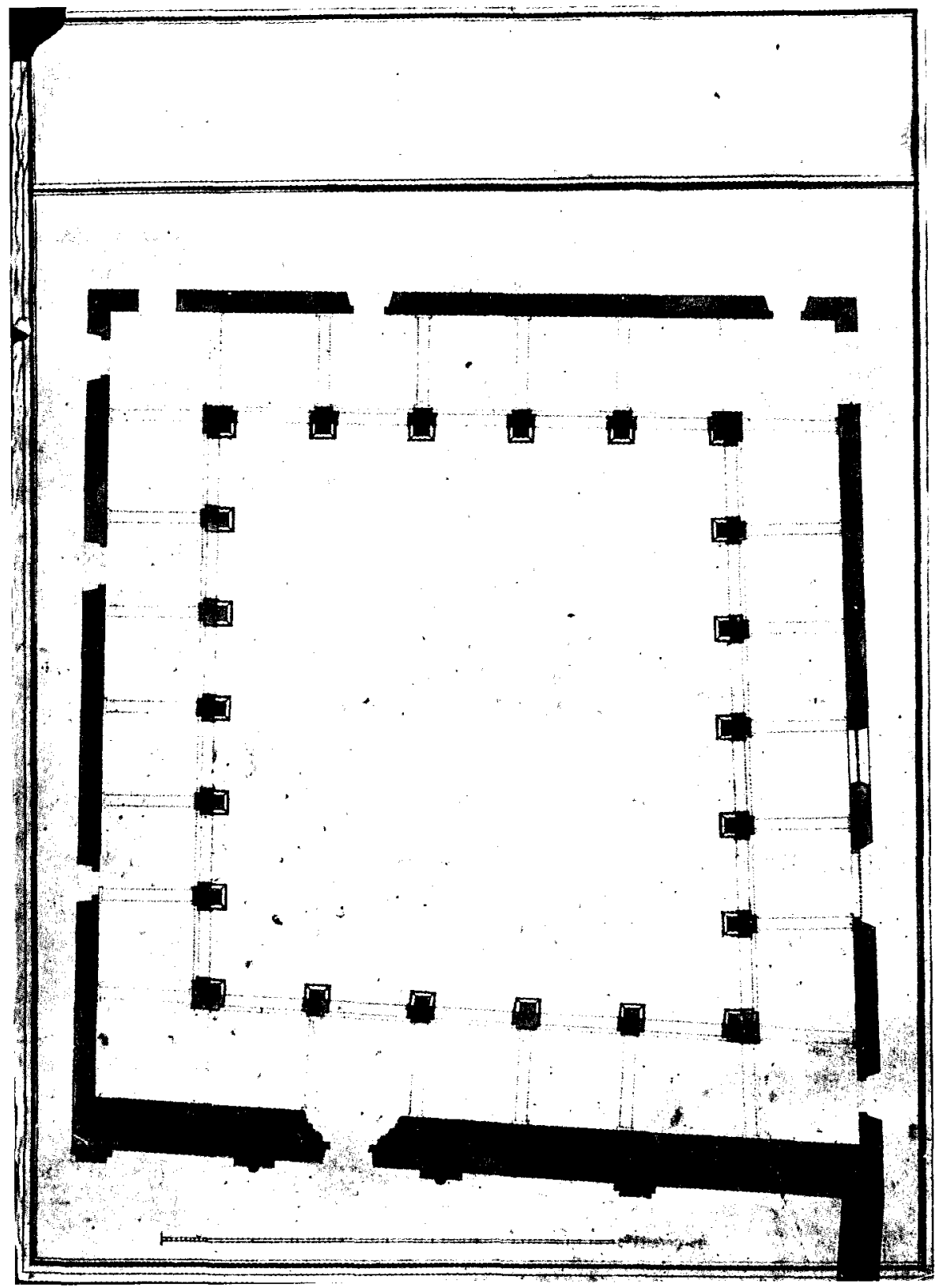

Fig. 8. Planta del claustro según Jacinto Sala, alias Marsal (1790). Igual al núm. 7 pero sin leyendas. 


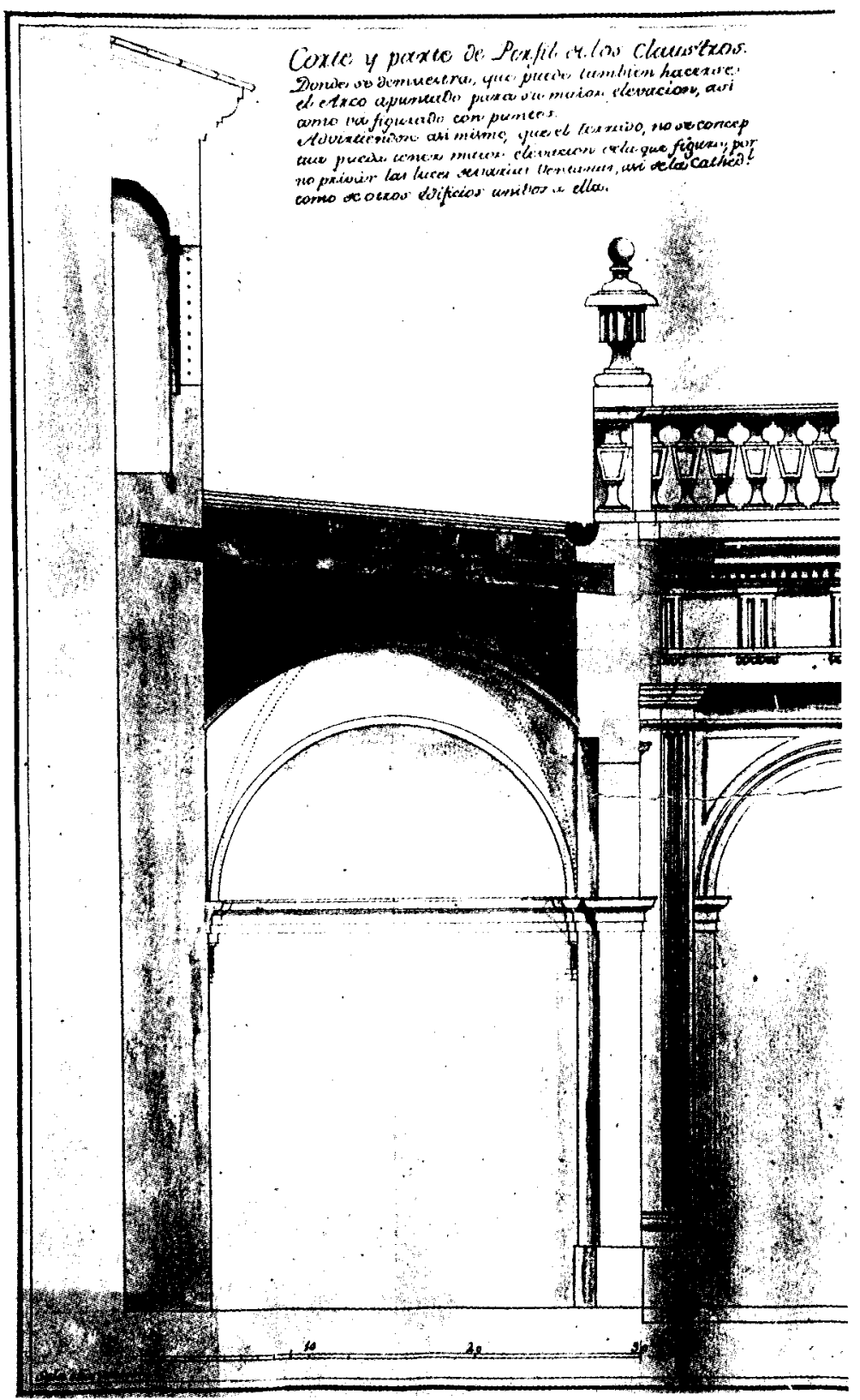

Fig. 9. "Corte y perfil de los claustros..." segun Jacinto Sala (a) Marsal (1790). 


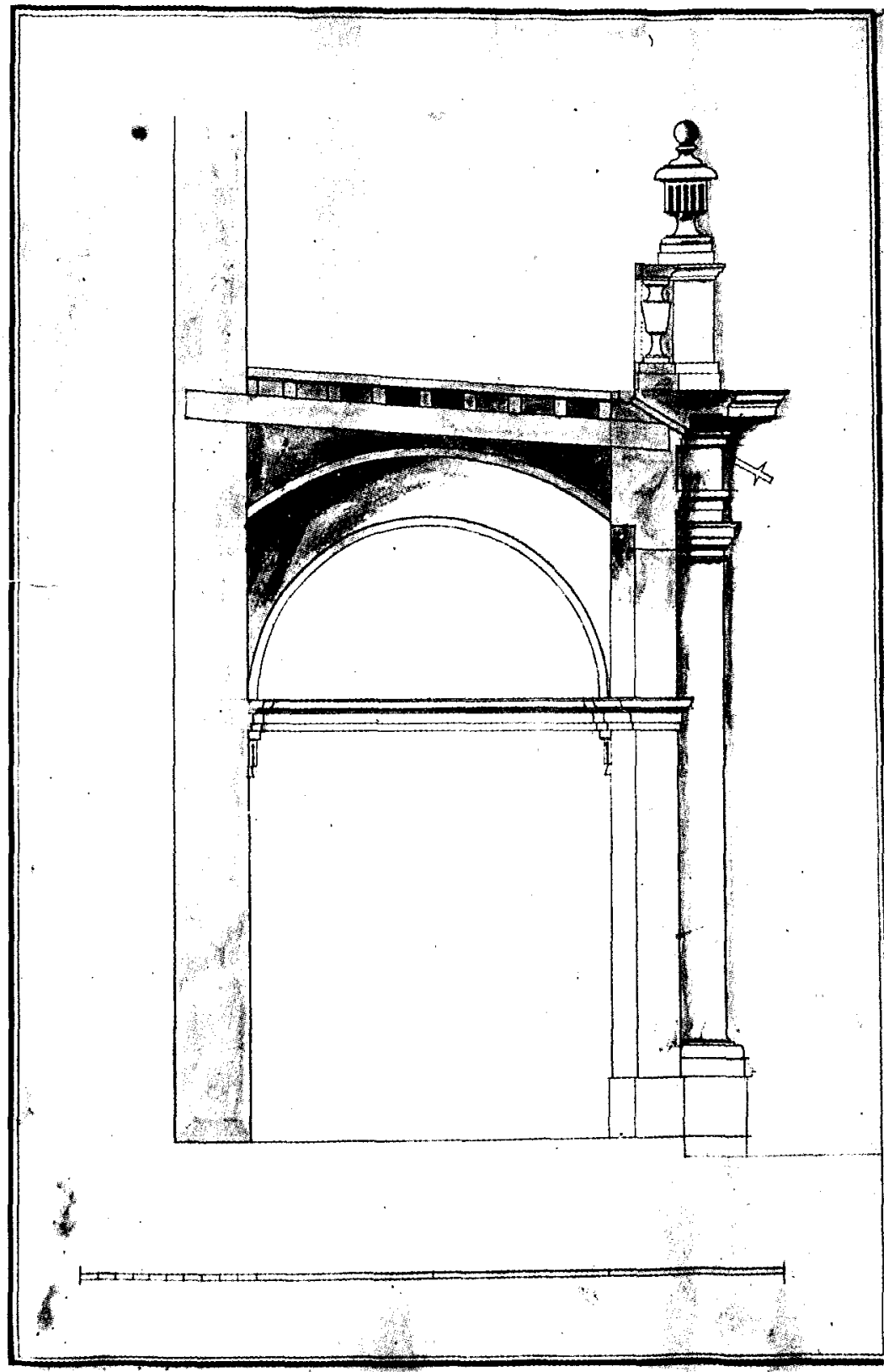

Fig. 10. Sección del claustro según Jacinto Sala (a) Marsal (1790). Semejante al núm. 9 pero sin leyenda. 


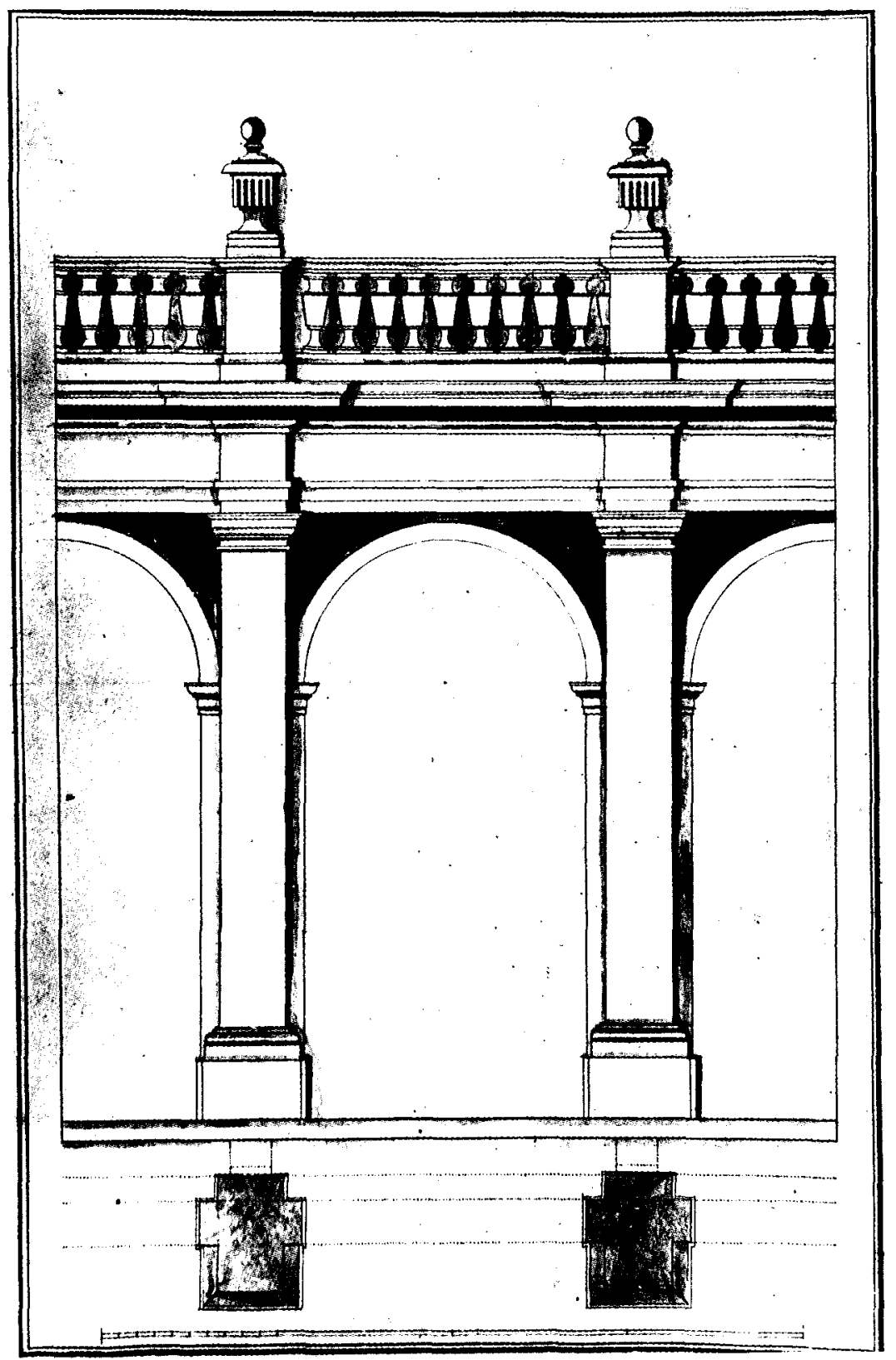

Fig. 11. Alzado de tres ramos del claustro según Jacinto Sala (1790). 


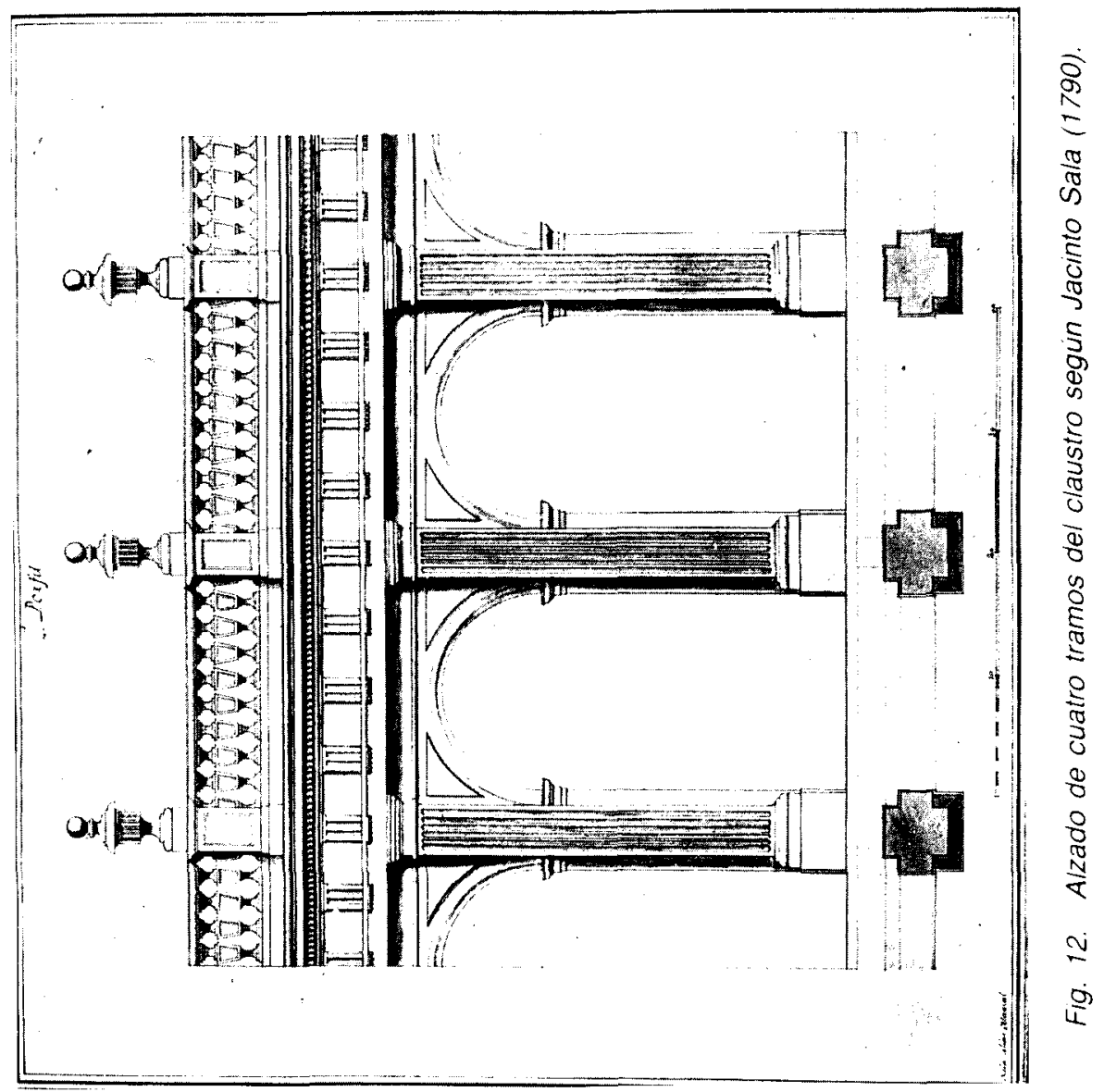



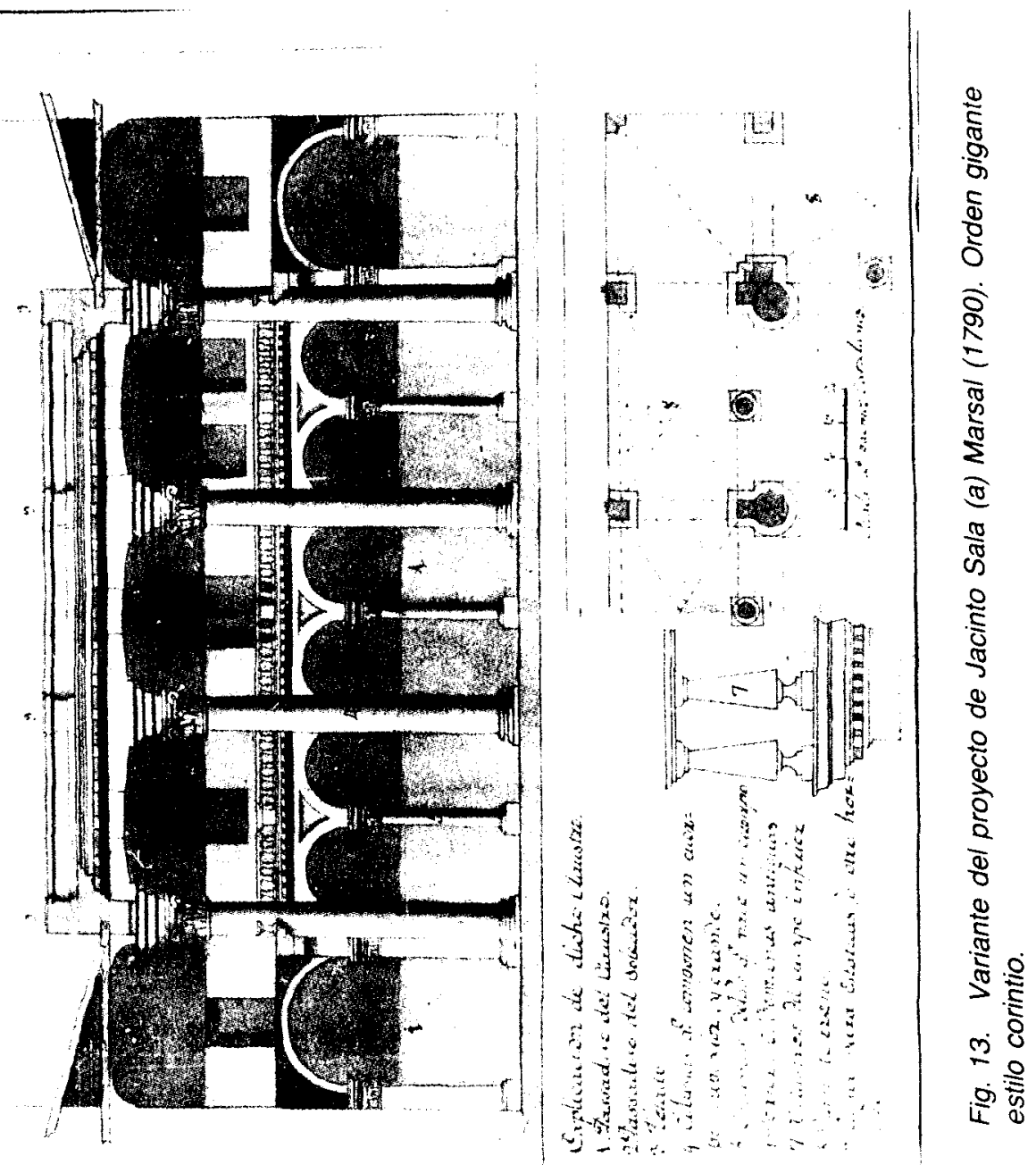


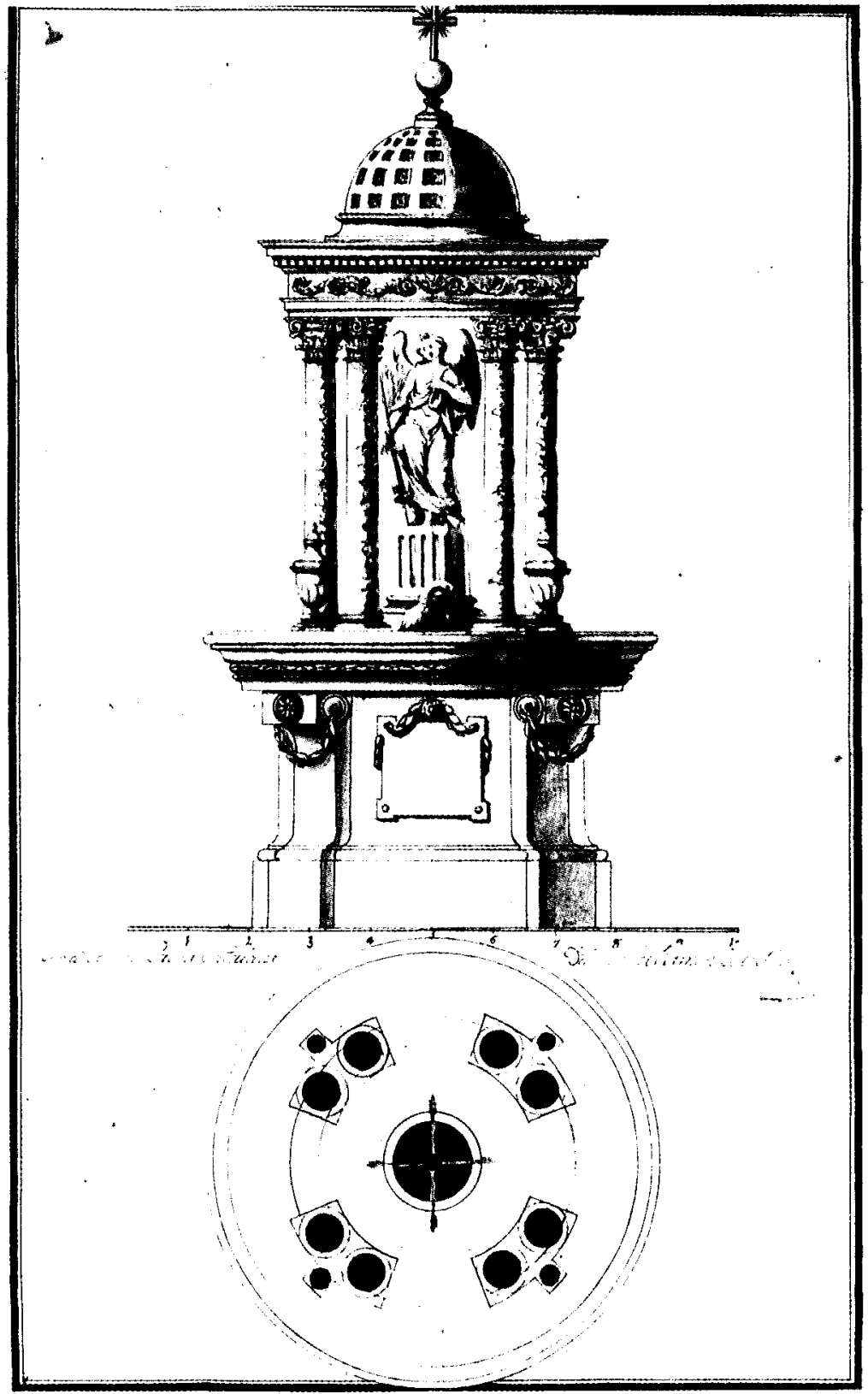

Fig. 14. "Font de les Oquetes", aguamanil de la Sacristía de la Seo Nueva de Lerida. Obra de Ramón Carcelles (1830). 
Ginisona r. ac Jistio 1832 .

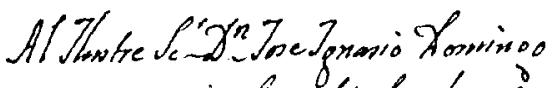

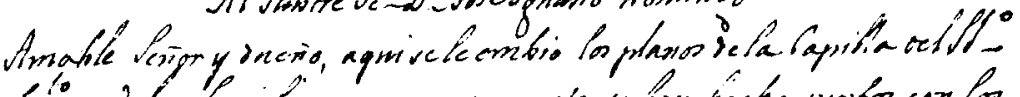

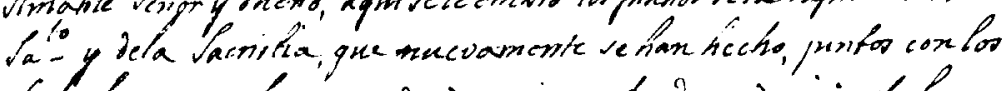

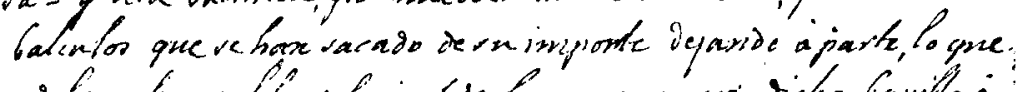

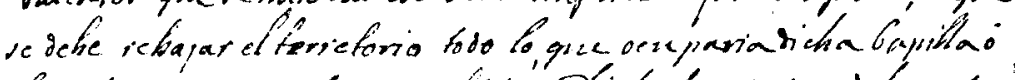

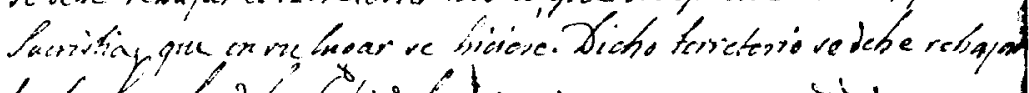

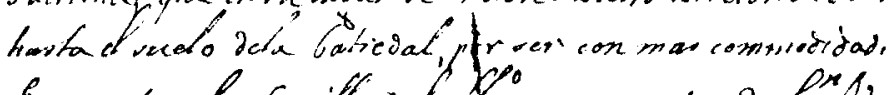

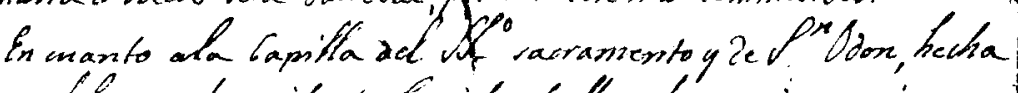

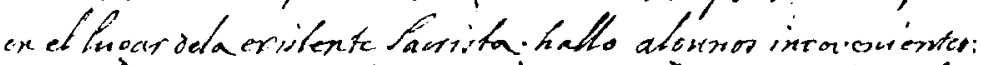

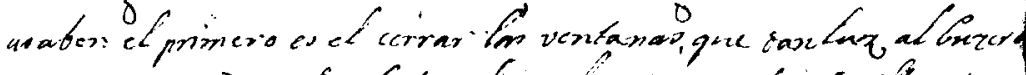

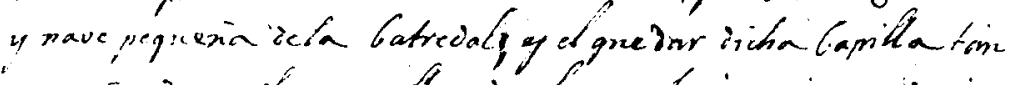

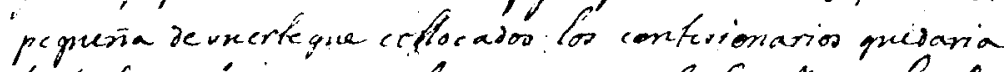

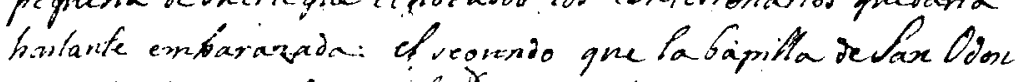

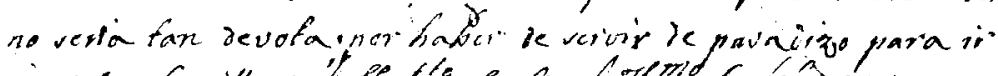

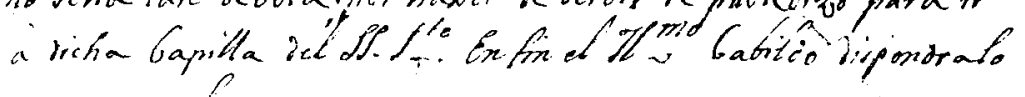
que mucor le parcoca.

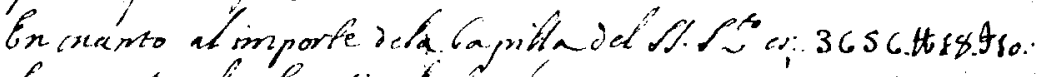

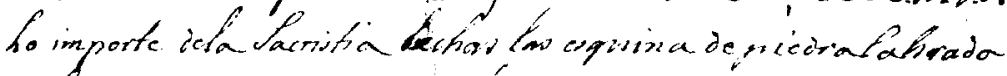

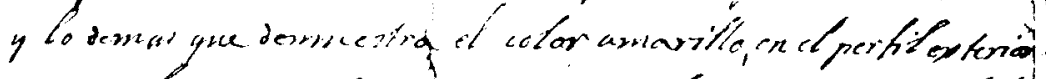

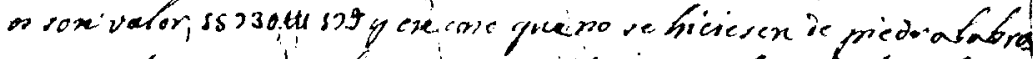

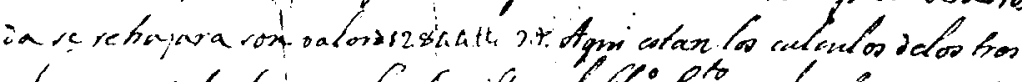

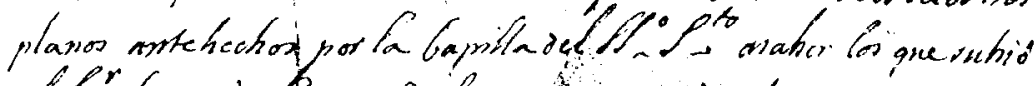

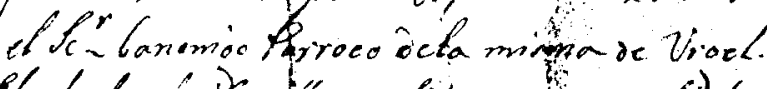

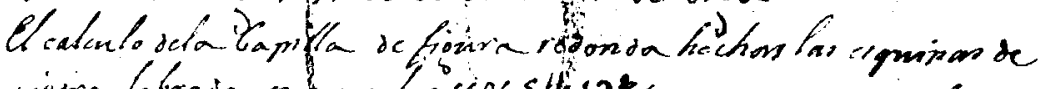

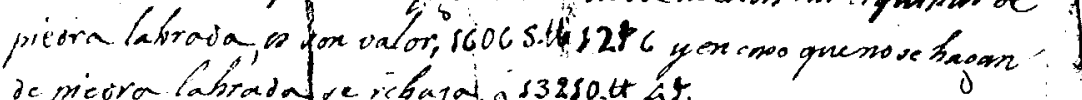

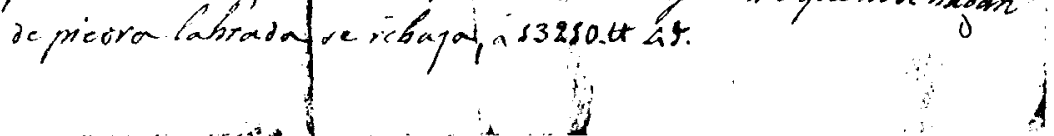

Fig. 15. Carta de Pablo Bertran al Cabildo desde Guissona el 1 de julio de 1832 


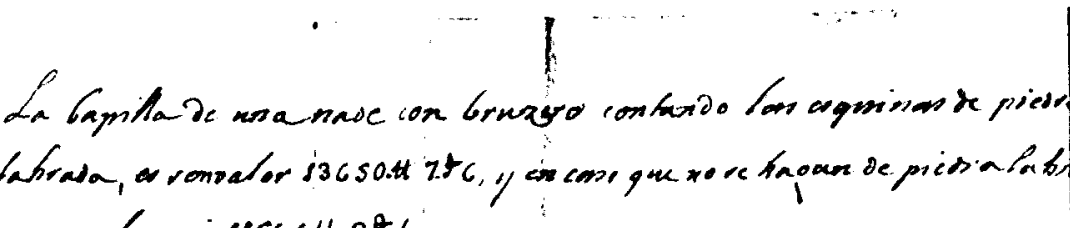
a re rchaja isssc.c.th 294 .

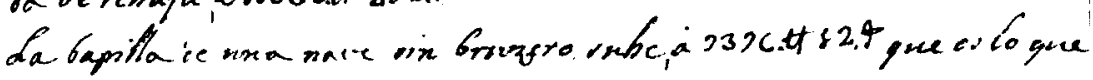
Nomekefiece recirle.

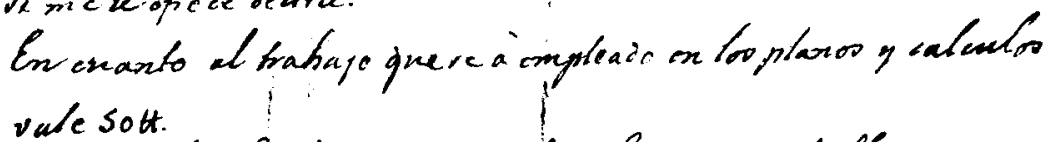

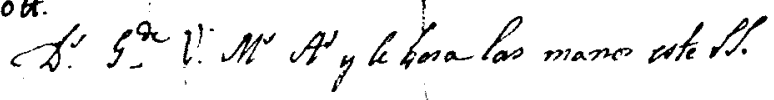
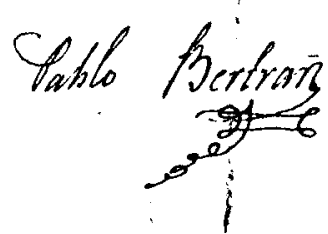

Fig. 15. Carta ... (continuacion). 


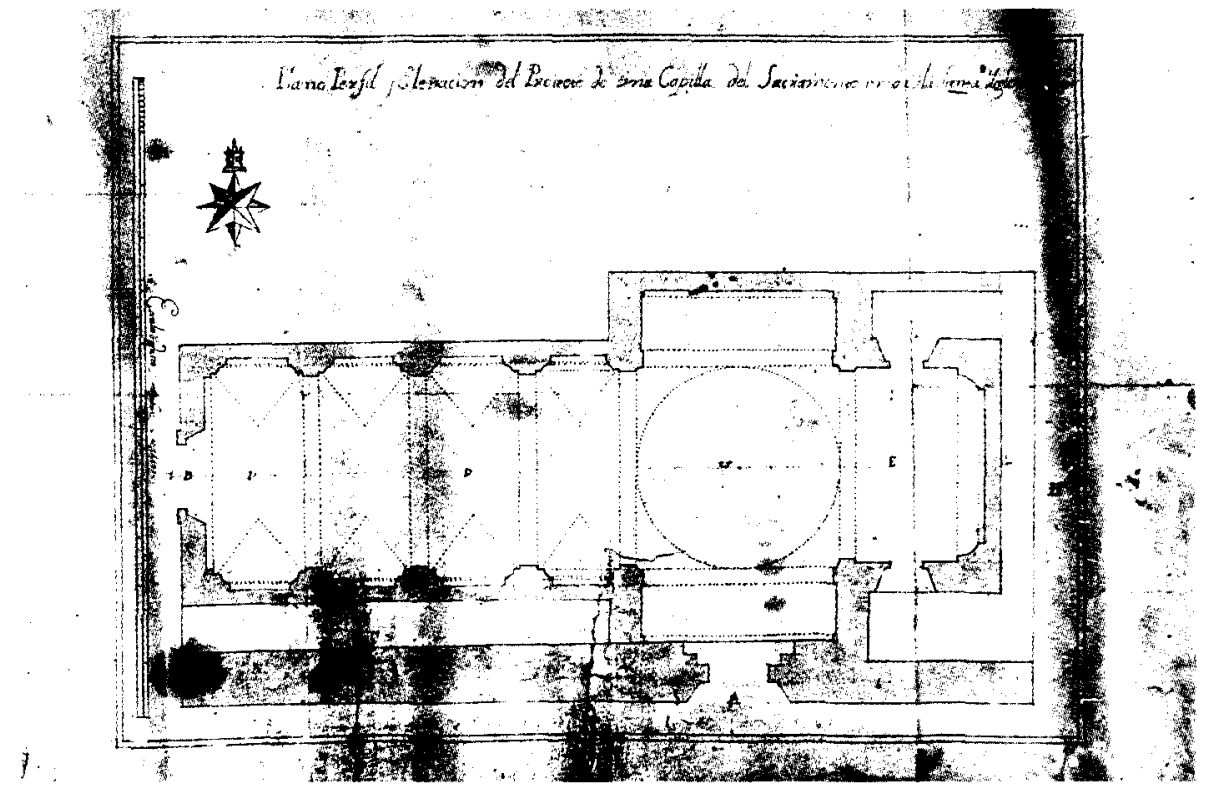

Fig 16. Planta de la capilla de Santisimo. con crucero. Pablo Bertran (1832).

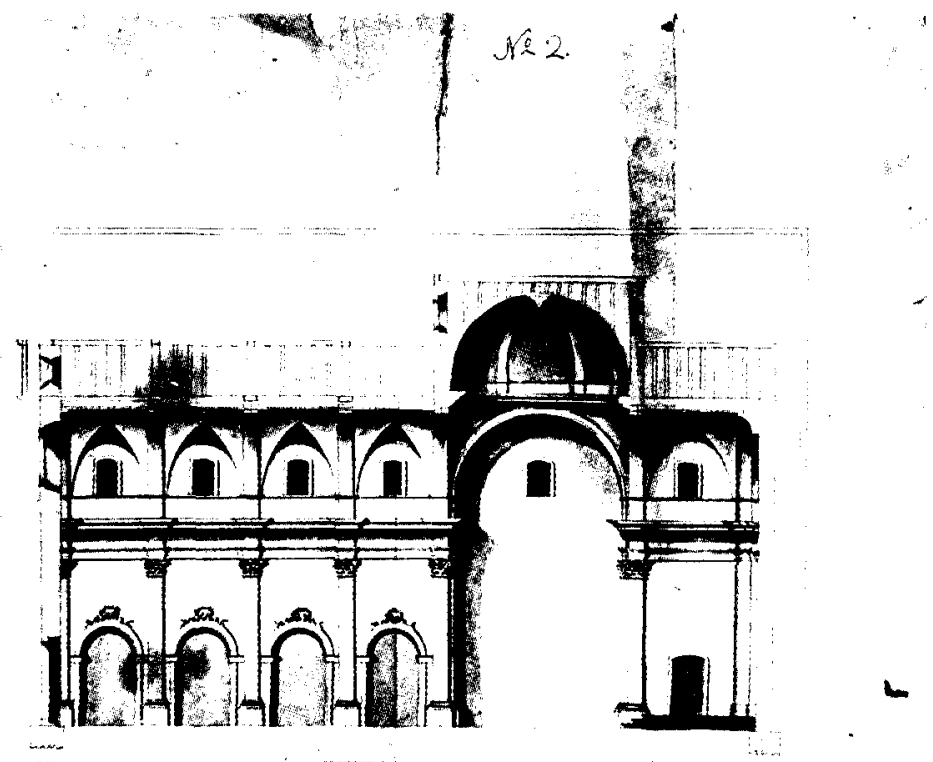

Fig. 17. Seccion de la capilla de Santisımo con crucero. Pablo Bertran (1832). 

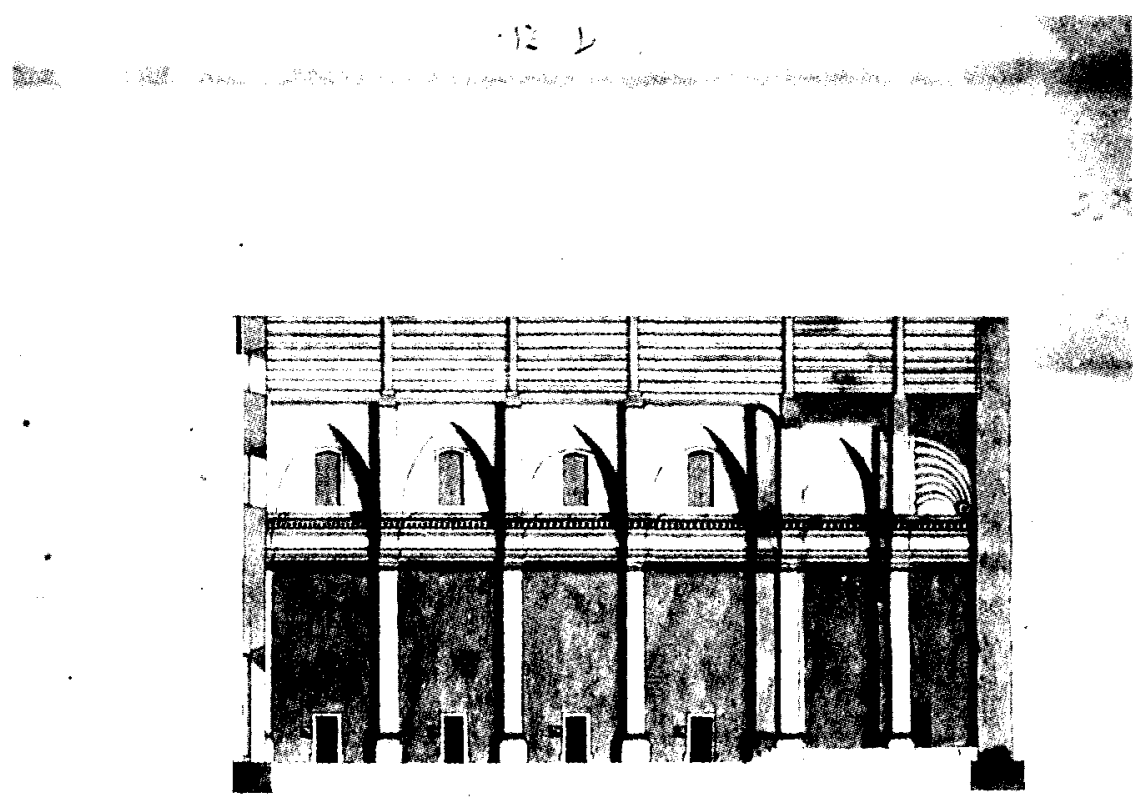

Xx,
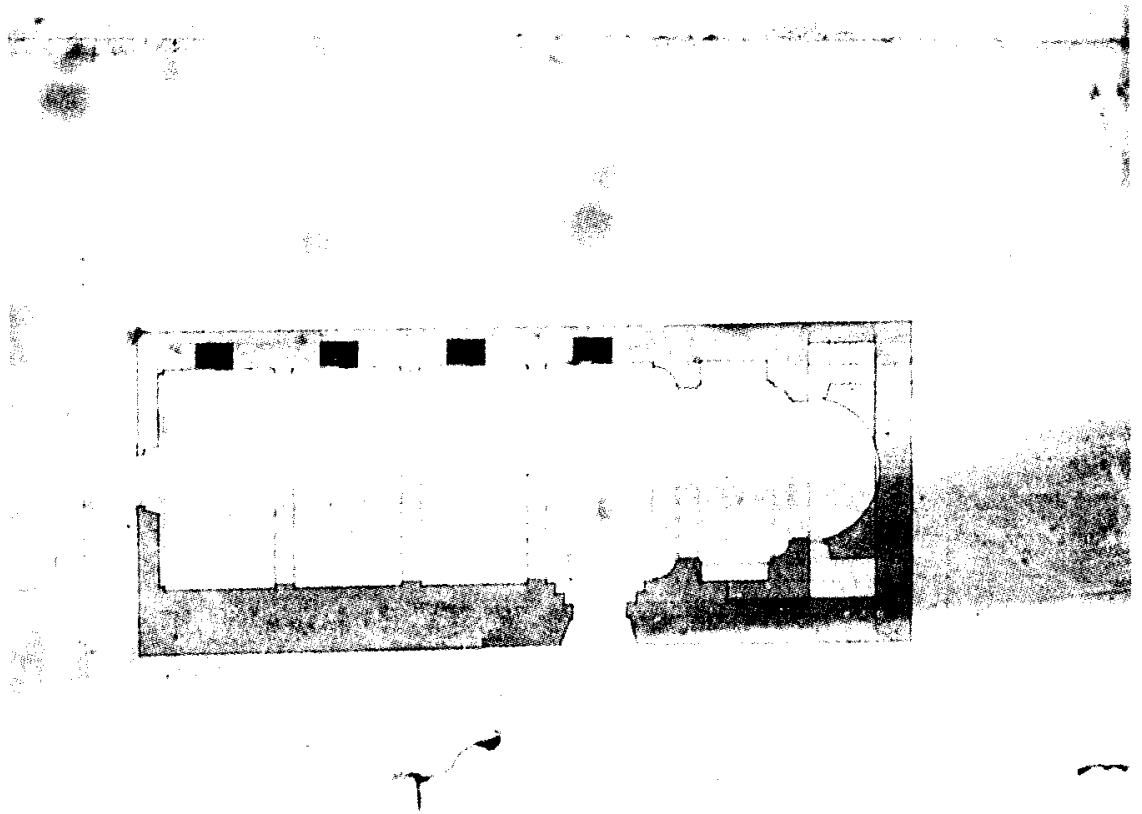

Fig. 18. Proyecto, planta y seccion longitudinal, de la capilla del Santisimo sin crucero. Pablo Bertran (1832). 


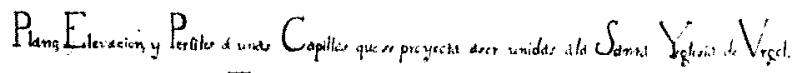

Explicidionony

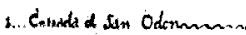

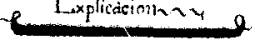

1. Yueriss de comunicalicieman..

4. Capill del Slese Sarnimientom

P

Lerfil Coriddo sobre sus cerresponientes

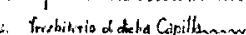

S. Cupilt de den Ddormony

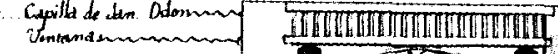
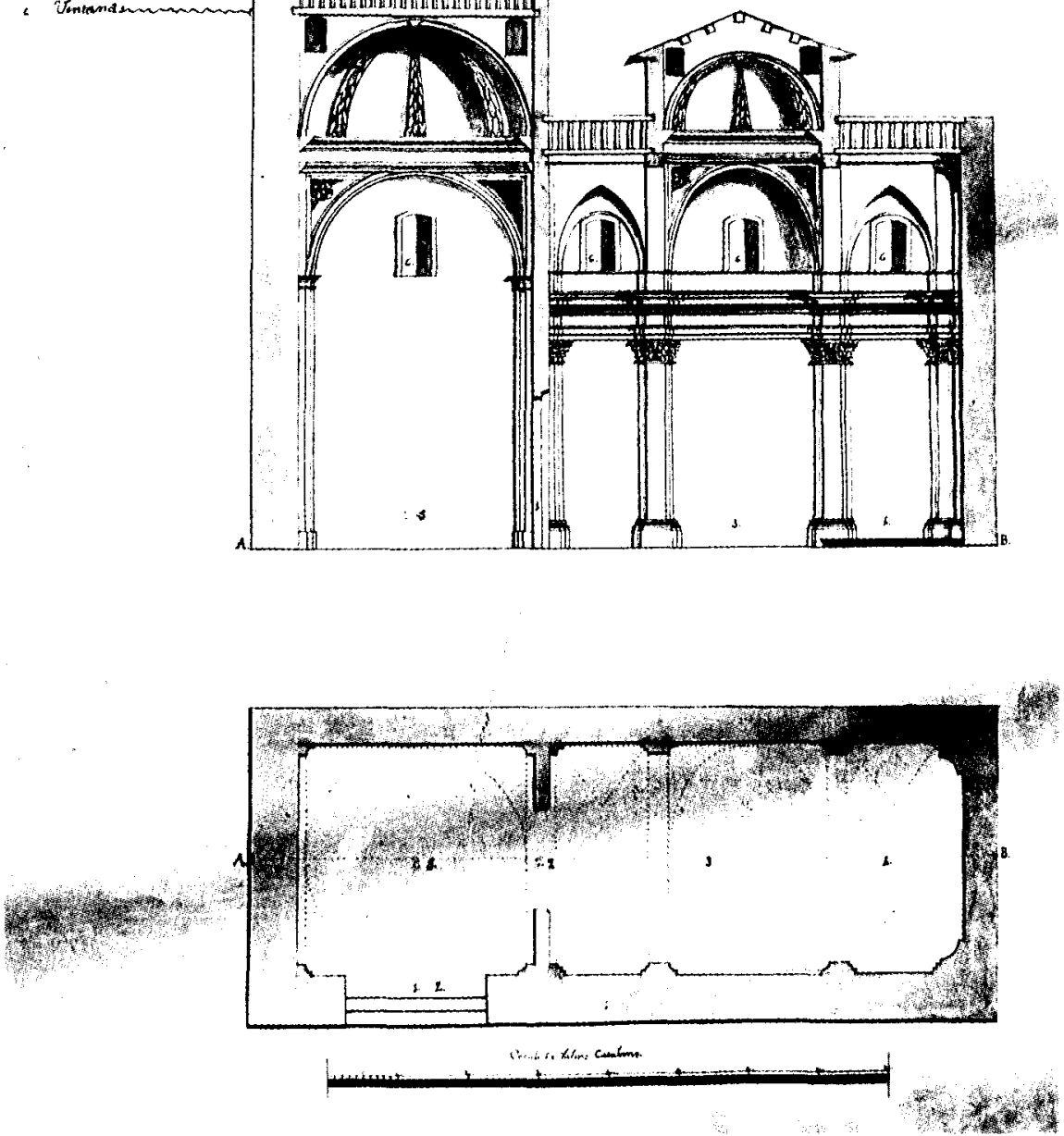

Fig. 19. Planta y sección de las capillas del Santisimo y de San Odon. Pablo Bertran (1832). 
JUAN BASSEGODA NONELL

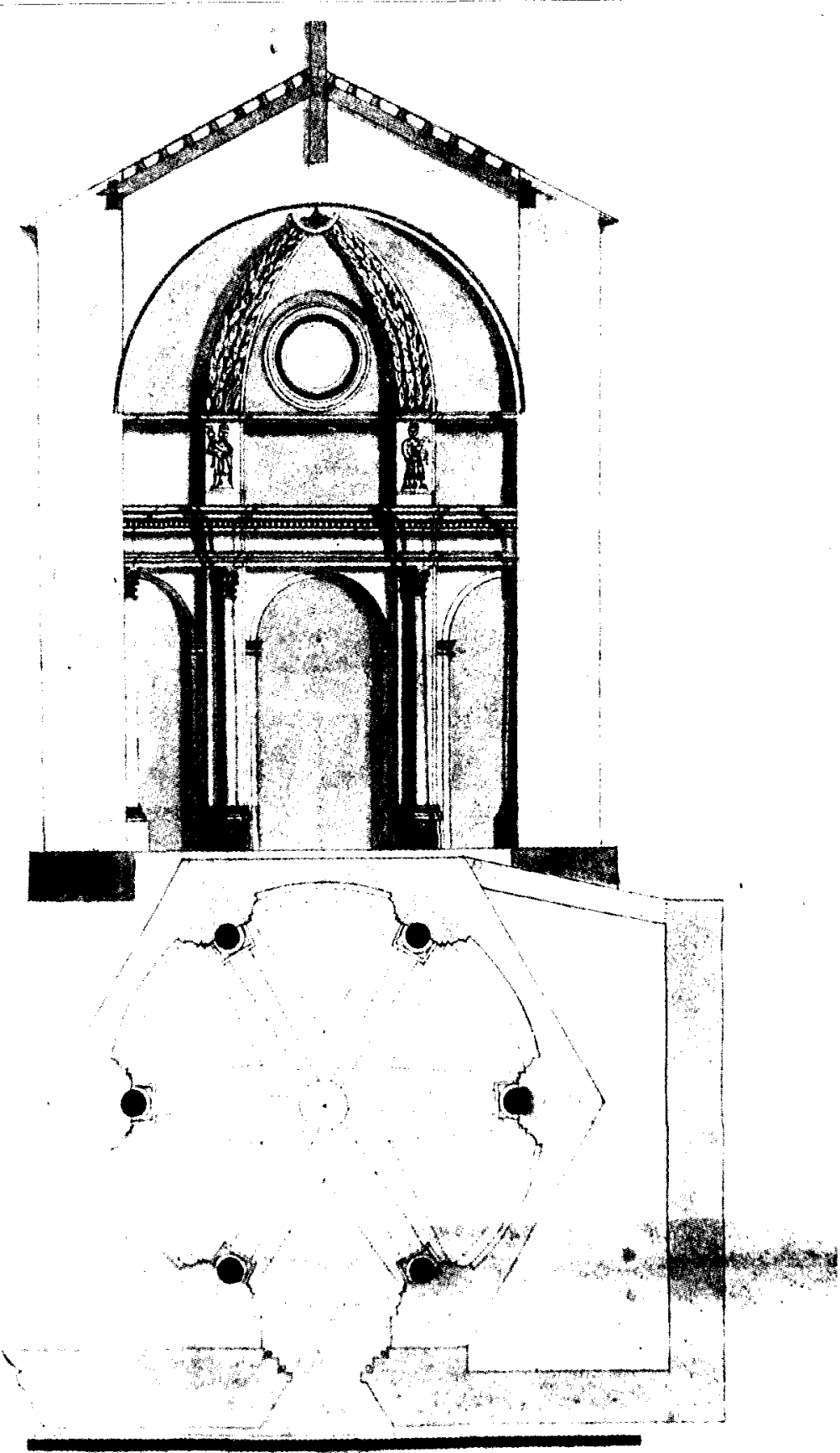

Fig. 20. Planta y sección de una capilla "redonda". Pablo Bertran (1832). 


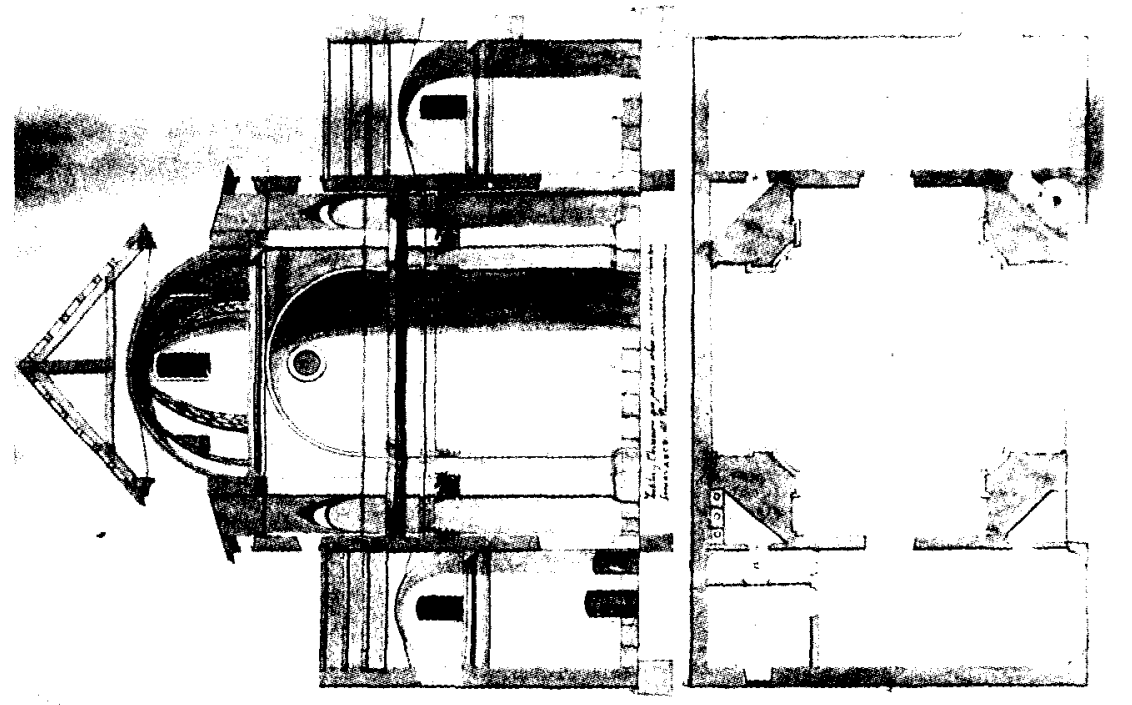

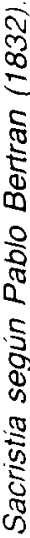

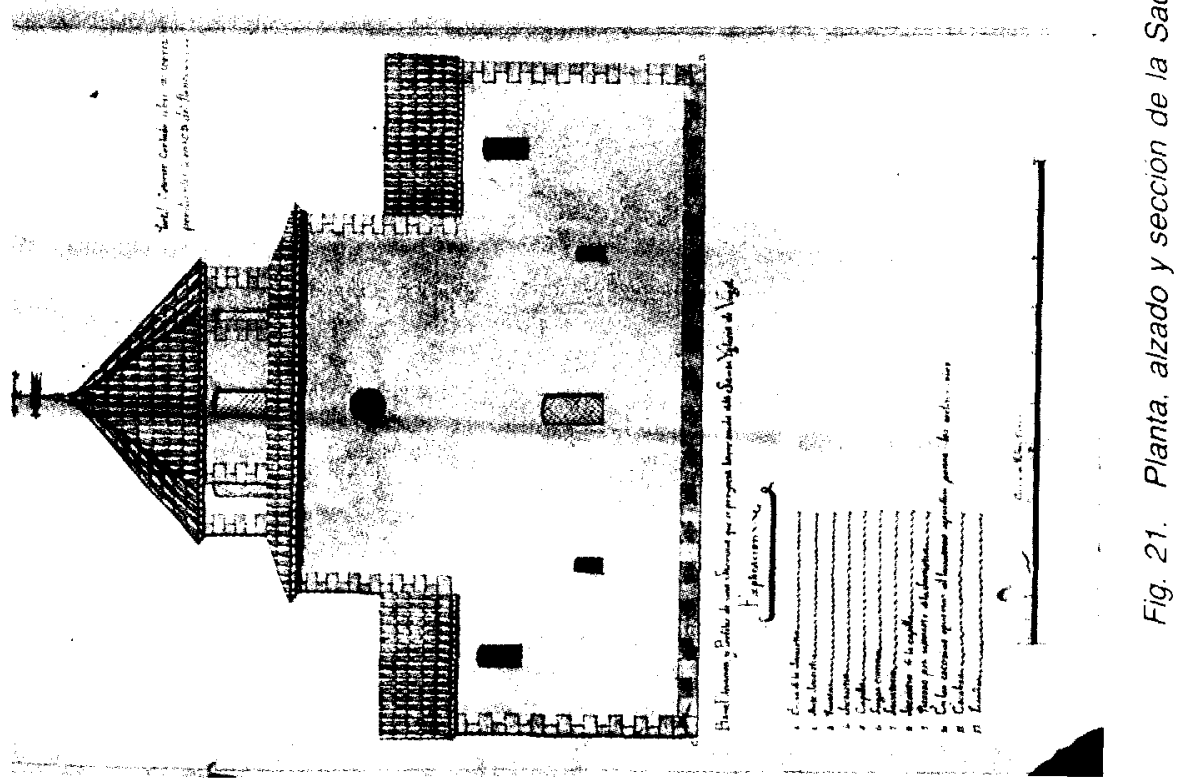




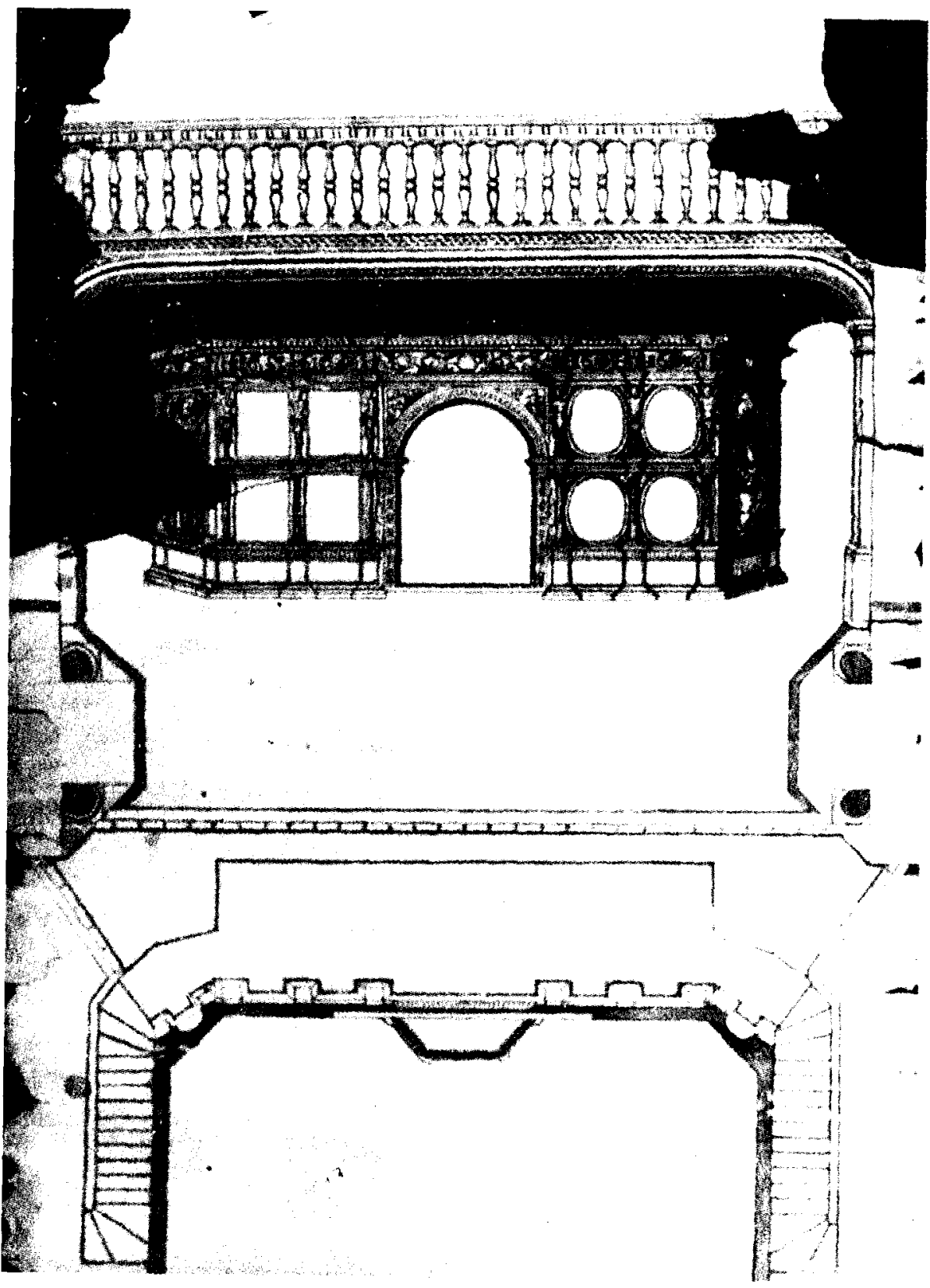

Fig. 23. Proyecto de trascoro sin fecha. 